\title{
Hearing Attention of Young Adult Sportsmen Prone to Alcohol
}

\author{
Portejoie Jean Aimé Tsiama ${ }^{1 *}$, Nicaise Léandre Mesmin Ghimbi ${ }^{2}$, \\ Maxh Sorel Moussoki Moussounda ${ }^{3}$, Forest Roosevelt Mabiala Ndziedi ${ }^{1}$ \\ ${ }^{1}$ Higher Institute of Physical and Sports Education, Marien NGOUABI University, Brazzaville, Republic of Congo \\ ${ }^{2}$ Faculty of Letters, Arts and Humanities, Marien NGOUABI University, Brazzaville, Republic of Congo \\ ${ }^{3}$ Unesco ENS Chair, Marien NGOUABI University, Brazzaville, Republic of Congo \\ Email: *lajoie25000@yahoo.fr
}

How to cite this paper: Tsiama, P. J. A., Ghimbi, N. L. M., Moussounda, M. S. M., \& Ndziedi, F. R. M. (2021). Hearing Attention of Young Adult Sportsmen Prone to Alcohol. Psychology, 12, 1025-1037. https://doi.org/10.4236/psych.2021.126061

Received: May 17, 2021

Accepted: June 27, 2021

Published: June 30, 2021

Copyright () 2021 by author(s) and Scientific Research Publishing Inc. This work is licensed under the Creative Commons Attribution International License (CC BY 4.0).

http://creativecommons.org/licenses/by/4.0/

(c) (i) Open Access

\begin{abstract}
Purpose: This article is about deals with the problem of neurocognitive impact due to alcohol and shows the drawbacks on the attentional performance of athletes. The study aimed at playing basketball or volleyball to male college students as a manager sport option. Methods: The variables at the center of the measures are: cognitive status, the profile of alcohol user, selective auditory attention, and efficiency of TDM to auditory information. Results: The results show impeccable mental performance for athletes with low consumption, while wide Specter of deleterious effects have been observed in athletes who drink excess alcohol. Discussion: On the one hand, memory degradation effects have been observed in alcoholics, chiefly characterized by delays in retrieving items followed by a large number of omissions. On the other hand, a neural disconnection effect has been suspected following ethyl toxicity, justifying early confused and confused attention in the presence of the target stimuli. In essence, it emerges that the "alcohol-cognition" couple functions together in a mode of competition rather than collaboration.
\end{abstract}

\section{Keywords}

Brain Impairment, Sports Scene, Alcoholic Beverage, Cognitive Performance, Selective Attention, Memory Impairment

\section{Introduction}

Ethyl alcohol or ethanol is a commonly consumed product, which is valued as a cultural object infiltrated with various social meanings (Ewart \& Culter, 1979; Dany et al., 2015; Varlinskaya \& Spear, 2015). It is contained in alcoholic beverages with effects which are exerted mainly on the brains of young adults who 
admit acute intoxication and would be responsible for several cognitive alterations (Oscar-Berman \& Marinkovic, 2003; Ben Amar, 2007; Pandza, 2012; Brust, 2010). Despite these devastating effects, many young adults allow themselves to abuse alcohol before embarking on their sports activities (O'Brien \& Lyons, 2000; Barnes, 2014). So how can athletes decide to drink alcohol before a sports competition? How does their cognition finally work on ethanol? These are the questions that have sparked contradictory debates between students whose altruism has led the research professors of the University Marien Ngouabi, specializing in psychology, to be able to include a number of questions in the repertoire of studies in psychological sciences backed by sports. From this point of view, the hypothesis on the neuropsychological effect of alcohol has been exclusively focused on the mental performance of sports populations.

The concept of "young adult" (Sesar et al., 2014) constitutes the specific population much more attracted to daily alcohol consumption (Scali et al., 2002). The "young adulthood" rotates between the course of adolescence, and before the maturity of adulthood itself (Gorwood, 2019). Before being able to characterize the cognitive profile of young adult sports drinkers of alcohol, it is necessary to underline the diversity of alcoholic beverages present in the Congolese social environment with a higher consumption among athletes than non-athletes and, more important among male athletes than in female athletes, the associated harmful consequence of which is the decline in physical and cognitive performance (Cox, 2013; Grossbard et al., 2009; LaBrie et al., 2009; Martens et al., 2006; Serrao et al., 2008).

Alcohol consumption by young athletic adults does not only occur within the framework sets by this study nor solely in spaces where vocational training takes place but also manifests itself in social behavior in the broader sense. Since these young people are at the center of an ambient society, where everyone finds the opportunity to drink as much as they want. The term alcoholism, coined in 1849 by Magnus Huss, professor of medicine in Stockholm, grouped together a set of psychic and somatic symptoms linked to alcohol abuse. It was only in the middle of the 19th century that alcohol could be problematized as a social danger (Briefer, 2012) and then as a substance of neurological damage (Menecier, 2010). In addition, in order to better manage confused emotional reactions, some athletes who are considered mentally fragile commonly resort to taking stimulants such as alcohol. Indeed, this behavior has the merit of potentiating the emotional aspects generated by the context of sports competition. Since competitive reality requires athletes to have capacities in attentional selectivity so as not to fail in the task of recognizing a target (Lemaire, 2006). This ability calls on the auditory system to better process the information it receives and to visually fix the target we are looking for in a sports scene. Once the selection of auditory stimuli is proven to be effective, it then seems possible for the player to better integrate the decision-making parameters (Mellers et al., 1998) necessary to build his attentional performance.

The word "alcoholism" has gradually been substituted by that of alcohol de- 
pendence or alcohol addiction. Since 2013, the DSM-5 introduced the diagnosis of substance use disorder and particularly alcohol use disorder. The abuse and dependence categories present in the DSM-IV are removed in favor of a continuum of clinical severity, regardless of levels of use. The intensity of the disorder is related to the number of diagnostic criteria presented by the patient (Cabé et al., 2019). In recent years, studies in neuropsychology have contributed to a better understanding of the heterogeneity of patients by specifying the existence of different profiles of brain and cognitive impairment (Ritz, 2012; Vabret, 2016; Rault \& Décamps, 2018). On the other hand, the deleterious effects of alcohol consumption have the force of cognitive toxicity (Menecier, 2010), to the point where the mechanisms underlying selective attention show the existence of nondemented cognitive deficits (Pierucci-Lagha \& Derousné, 2003) while the overall properties of sensory stimuli are denatured and decreased in effectiveness. The concept of selective attention distinguishes all the attentional processes from mechanisms linked in a non-specific way to the notion of arousal (Tarroux \& Auvray, 2012). In the sports sphere, the study of the scientific literature identifies selective attention as an important determinant in building prestigious actions leading to success. Success in interactive sports (Cox, 2013) depends fundamentally on the attentional selectivity of each player, which derives its efficiency as much from the perceptual discrimination of stimuli as from the mental representations of the athlete (Poucet, 2005).

Furthermore, one could object that in competition the simultaneous verbal contributions of the supporters and those of the coach constitute a potential pole of dispersion of the auditory attention to which must be added to the verbal threats of the public of the opposing team. These parameters are prickly to burden the attentional mechanisms of an athlete, making him less active because he would tend to process information both from internal and external sources. However, the mergin of various informational sources would probably characterize a saturation of stimuli, with in particular the limitation of the capacities of the visual system and the auditory system. In fact, while verbal feedback from the coach (Tsiama et al., 2019) and the public can constitute effective prevention of strategic errors in the field, they can at times become sources of frustration and destabilizing emotional reactions at the outset, of diffuse auditory attention among their own elites.

Yet, studies have observed the psychostimulant effect of alcohol, leading to behavioral dehinibition and impaired alertness in both simple organisms and humans (Singh \& Heberlein, 2000). In terms of levels of consumption, the neurocognitivist approach recognizes the evidence of behavioral abnormalities following a blood alcohol level of the order of $0.5 \mathrm{~g} / \mathrm{l}$ corresponding to the absorption about three glasses of alcoholic beverages on an empty stomach. Findings from several studies show that this dose can apparently trigger a string of disorders capable of impairing the performance of cognitive tasks (Astley, 1999; Ritz et al., 2012; Sampson, et al., 2000; Yanni \& Lindsley, 2000).

Attention induces very specific effects in various parts of the human brain. 
Thus, the technology convinces us with regard to the major damage that it is possible to identify from the signals in the different cortical areas. This better explains the question of early or late treatment (Bertoz, 2009) on the cognitivemotor level. Likewise, brain studies by measurements of evoked potentials have shown cognitive alterations of varying severity in patients with chronic heavy alcohol consumption. Scientific findings have confirmed that cognitive impairment is extremely common in a population of young alcohol-dependent subjects. More easily, these disorders concern working memory (E.T. $=0.89$ with SD $=0.89$ ), in particular visual, but also visuomotor capacities, abstraction capacities, as in more elaborate functions such as the strategy of organizing tasks. Numerous neuroscientific studies (Kalivas \& Volkow, 2005; Zeisser et al., 2013; Wilson et al., 2004) concerning the metabolic activity of the brain have made it possible to identify the areas of the brain associated with the urge to consume a substance in subjects who are addicted to substances such as alcohol dependence. Observation of neuronal substrates by PET has revealed the activation of certain areas of the brain associated with the substance consumed (Battaglia \& Gierski, 2014). On the athletic field, the behavioral consequences would be more evident when an athlete could hardly perform cognitively.

\section{Methodology}

\subsection{Participants}

The sample is made up of 48 male university students, whose 26 are in the first year sporting non-graduate (average age: 20.77 years; SD =1.32). The other 22 are students in the third year non-graduate in sporting (average age: 22.76; E.T = 0.89) who have chosen Basketball or Volleyball as sports specialties. All the recruited participants consume alcohol, inside or outside the university, whose 18 have an occasional consumption while 27 of them have a regular consumption. The average age of all athletes is 23.11 years $(\mathrm{SD}=2.55)$. A minimum weekly hourly volume of 8 hours of training in a federal club has been adopted as a criterion to validate sporting practice. Athletes who were chosen have sporting experience of 1 to 6 years depending on their age. Beginners join the same disciplines as experienced athletes and have sporting experience of less than a year.

\subsection{Procedure}

The participants were recruited at the Higher Institute of Physical and Sports Education through a pre-questionnaire mentioning a closed question about alcohol consumption. This pre-questionnaire also made it possible to obtain sociodemographic characteristics (age, sex, level of study, and sporting experience). The data from this pre-questionnaire guided the selection of those who should be the aim of this study. Thus, those who did not drink alcohol were excluded from the final sample. Upon arrival at the Laboratory, each participant began by giving their informed consent for voluntary participation without remuneration in the proposed tasks. They were divided into two groups (beginners and expe- 
rienced athletes). First, participants were taken to the Center Medico-Sportif at Alphonse Massambat-Débat Stadium to undergo a neuropsychological examination including assessment of cognitive status. Subsequently, they were placed in a quiet and adequately lit room where they answered the questionnaire on their alcohol consumption. They were subsequently given an auditory attention task.

\section{Measures}

\subsection{Montreal Cognitive Assessment (MoCA Test)}

The MoCA test was developed by (Nasreddine et al., 2005). This tool is designed for the assessment of mild cognitive dysfunction. It assesses functions such as attention, concentration, executive functions, short-term memory, language, visuospatial skills, abstraction skills, arithmetic, and orientation. The execution time is approximately ten minutes. The maximum number of points is 30 . Scores on the MoCA range from 0 to 30, with a score of 26 and more generally considered normal (Smith et al., 2007; Ismail et al., 2010).

\subsection{Michigan Alcoholism Screening Test (MAST)}

The Michigan Alcohol Screening Test (MAST) (Selzer, 1971) was the first selfreported alcohol screening tool, which is today considered a highly important clinically important tool (Carey, 2002). Its commonly used short forms have been administrated in more than 500 studies in various populations. We chose the MAST reduced to 24 items (Selzer, Vinokur, \& Rooijen, 1975). This instrument is a self-assessment measure that takes approximately 10 minutes to administer. The participants answered in writing and the points awarded according to the answer vary from 0 to 5 . In case of "yes" answer, certain items are rated 1 point; another 2 points and another 5 points. The total score is 53 .

\subsection{Broadbent Selective Attention Test (TASB)}

(Broadbent, 1958) is model assesses selective attention. This test is basically designed to study phenomena of memories and auditory attention. It is applied in the study of an ability of a person to pay attention to several messages at the same time (Lemaire, 2006). During the 1950s, this ability was studied using the "dichotic listening" technique (Phélip, 2014). With this technique, the subject is simultaneously presented with two verbal messages, one to the right ear and the other to the left ear. The person should spot the main message ignoring the secondary message. Originator studies have reported the advantage of the right ear for recalling verbal material. This dominance has classically been interpreted as resulting from the dominance of the left hemisphere (Seron \& Van der Linden, 2014). In the dichotic (words and numbers) listening condition, participants should listen in one ear, the main message (containing 7 words) pre-recorded on a PC "A" computer, using headphones. Then, simultaneously, listen to a secondary message (also containing 7 words) pre-recorded in the other ear through a PC " $\mathrm{B}$ " computer. The participant's task was to repeat the message with one 
ear immediately after hearing it, even if another message was simultaneously scrolling in the other ear. Only the main message (followed only once) from the right ear should be repeated.

\subsection{Statistical Analyzes}

Statistical analyzes were performed using SPSS software, version 18. First, the variables were analyzed descriptively, with calculation of means and standard deviations. An intergroup and intragroup analysis was subsequently carried out. The comparisons of the averages were carried out by the unpaired Student's t-test and then the comparisons of the percentages were carried out by the Chi2 Persons test. The significance level used for the tests was set at a value less than or equal to $5 \%$.

\section{Results}

After taking the test, $66.66 \%$ of athletes with a habit of consuming alcohol have mild cognitive impairment compared to $5.56 \%$ of athletes who do not have this habit. In addition, $29.63 \%$ of regular alcohol drinkers reported moderate cognitive impairment while $94.44 \%$ of non-drinkers reported no cognitive impairment. However, at the end of the measurement by MoCA, sportsmen and women who drink alcohol testified an average score of less than $26(\mathrm{M}=19.22 \pm$ 0.38 ), which supposes that the sample of sportsmen who drink is declared positive for $d$. cognitive status damaged by alcohol. While non-alcoholic athletes produced an average score $(\mathrm{M}=27.78 \pm 0.57)$ little similar and slightly improved to that of normal controls $(M=27.4)$ in the initial study establishing the MoCA. There is a very significant difference between the two groups with regard to the effect of alcohol on cognitive processes $(\mathrm{t}=8.81, p<0.0000)$ : cognitive performance is better when athletes do not drink alcohol. (See Table 1)

At the end of the statistical processing, the results in Table 2 show that the scores for the "certain dependence" dimension, measured at MAST, are not similar between the two groups of athletes. Since the descriptive statistical results and the t-test showed that there is a significant difference between beginners and advanced $(p<0.05)$.

Table 1. MOCA test subscale score.

\begin{tabular}{|c|c|c|c|c|}
\hline & $\begin{array}{l}\text { Beginners Athletes } \\
(\mathrm{n}=18)\end{array}$ & $\begin{array}{l}\text { Confirmed sportsmen } \\
\qquad(\mathrm{n}=27)\end{array}$ & $t$ & $P$ \\
\hline Severe impairment & $0 \%$ & $0 \%$ & & \\
\hline Moderate impairment & $0 \%$ & $8(29.63 \%)$ & & \\
\hline Mild impairment & $1(5.56 \%)$ & $18(66.66 \%)$ & & \\
\hline No breach & $17(94.44 \%)$ & $0 \%$ & & \\
\hline MoCA Test & $27.78 \pm 0.57$ & $19.22 \pm 0.38$ & 8.71 & $<0.00001^{\star}$ \\
\hline
\end{tabular}

Results significant at $p<0.05$. 
Table 2. Alcoholism rate by level of sportsmanship measured at MAST.

\begin{tabular}{ccccc}
\hline & $\begin{array}{c}\text { Beginners Athletes Confirmed sportsmen } \\
(\mathrm{n}=18)\end{array}$ & t $(\mathrm{n}=27)$ & $p$ \\
\hline No consumption related issues & No & No & & \\
Probability of alcohol dependence & No & No & & \\
Dépendance certaine & $31.33 \pm 1.55$ & $47.44 \pm 1.03$ & -10.02 & $<0.0001^{*}$ \\
*Significant result at $p<0.05$. & & & &
\end{tabular}

Analysis of the data from the present study indicates that $27.77 \%$ of nondrinking athletes answered "yes" the pre-questionnaire question related to the word message, while $10.34 \%$ of drinking sportsmen expressed themselves favorably. Likewise, the performances recorded in relation to the message of the figures show a percentage of $88.88 \%$ of negative responses among non-alcohol drinkers against $86.21 \%$ of similar responses among sporting drinkers. The difference between the two groups, regarding the two types of messages, was not significant at $p<0.05$. In the case of a word message (Khi-2 $=1.57, p=0.0213$; with Yates correction) while in the case of a digit message (Khi-2 $=0.11, p=0.74$; with Yates correction). It could then be concluded that alcohol did not influence the incorrect answers obtained on the word and number test (See Table 3).

\section{Discussion}

The objective of this research was to ensure that, in sporting practice, the function of attention is fundamental for mental performance. But that this can get worse with excessive alcohol intake. In view of the results of Table 1, if the cognitive performances between these groups differ, it would be possible to argue that the spatial cognition of the athletes diverges notably despite the appearance of the level of the athletes from the point of view of their physical and technical preparation. The attentional capacity would rather be impaired with regard to an absolutely damaging impact with a poor cognitive status. Furthermore, in this study, the analysis of the average fluctuation in attention focused on the main message. The primary message is from the right ear while the secondary message is from the left ear.

We presented in Table 2, the average performance of the main message recalls in dichotic listening obtained in relation to the differences between sportsmen, according to the messages of the words and the numbers. Using the intrasubject chi-square calculation, we see in "non-drinkers athletes" a fluctuation in performance at the message of the words. In order to know how the fluctuations evolve in alcohol dependents, we carried out a contingency table analysis. This analysis gives the distribution of athletes of different levels of practice between alcohol drinkers and non-drinkers. The chi-square calculation indicates a link in the distribution of people within the different groups. Although in appearance there does not seem to be any difference between the heaviest drinkers and the 
Table 3. Percentage of recall of main message listening dichotically.

\begin{tabular}{cccccc}
\hline & & \multicolumn{2}{c}{ Word Message } & \multicolumn{2}{c}{ Numbers message } \\
\cline { 3 - 6 } & & $\mathrm{RC}$ & $\mathrm{RI}$ & $\mathrm{RC}$ & $\mathrm{RI}$ \\
\hline Beginners Athletes & $\mathrm{n}=18$ & $5(27.77 \%)$ & $12(66.66 \%)$ & $2(11.11 \%)$ & $16(88.88 \%)$ \\
Confirmed sportsmen & $\mathrm{n}=27$ & $3(10.34 \%)$ & $26(89.65 \%)$ & $1(3.45 \%)$ & $25(86.21 \%)$ \\
Chi-square corrected & & 1.55 & \multicolumn{2}{c}{0.11} \\
$p$-value & & \multicolumn{2}{c}{$p=0.21$} & \multicolumn{2}{c}{$p=0.74$} \\
\hline
\end{tabular}

RC: Correct reminder or organized message; RI: Incorrect callback or disorganized message. Non-significant result at $\mathrm{p}<0.05$.

low drinkers, but the results thus obtained tend to show a greater attentional capacity vis-à-vis the behavior of athletes less inclined to alcohol against a high level of distraction among heavy users. The conception of attention with limited resources thinkd that several complex tasks performed simultaneously would result in an accumulation of information, thus exceeding the available attentional capacity.

(Abernethy, 2001) emphasizes that the athlete should constantly pay attention to several stimuli, without this necessarily interfering with the tasks. Thus, in the case of this study, a basketball or volleyball player would focus on the ball but also on his teammates than on that of his opponents, without there being any regression in his mental performance. Moreover, (Target \& Petitjean, 2016) has shown in its study of elite athletes from different disciplines, including handball and sprinting, that selectivity and attentional power were predictive of mental performance on the sports field. However, our results show that alcohol alters the mental performance of athletes in general, and attentional in particular, going so far as to prevent them from celebrating the experience of mindfulness which fundamentally depends on selective attention (Décamps, 2012).

Regarding more or less long time during which responses were obtained including the profusion of omissions of words and numbers, our results are in agreement with the principle defended in cognitive psychology, concerning the mechanisms of attention, operating in conjunction with pre-attentive immediate memory (PIM). The latter has been studied in detail, especially under the leadership of Sperling, who called it sensory memory. Nowadays, we speak of echoic sensory memory in the case of hearing. The representations of auditory information present in echoic sensory memory are called echoes. Sensory memory (or immediate pre-attentive memory) operates before the attentional filter. It is at this level that it is possible to understand the shortcomings and flaws of participants in the Broadbent Selective Attention Test (Table 3). Because their PIM could only retain echoes for only a short time. This duration is only on the order of a few seconds for echoes. Brief retention acts as a buffer, which would have allowed them to barely select representations (in terms of echoes) of information that was not abundant in the experiment.

This is explained by the fact that alcohol drunk regularly by athletes is the 
cause of some cognitive disorders, resulting in slowness and cognitive confusion. Since alcohol-cognition interrelationships are multifatorial (Cabé et al., 2018) and ingested alcohol is directly absorbed in the duodenum and then distributed through the bloodstream until it crosses the blood-meningeal barrier. Even when consumed over short periods of time, alcohol causes direct damage to brain tissue. By the extent of its action, it acts on membrane phospholipids and modifies the plasticity of brain cells, resulting in changes in the circulation of neurotransmitters. While in the past, research into alcohol-related cognitive disorders was limited to Korsakoff syndrome or alcoholic dementia, recent studies report both structural and functional brain damage in alcohol dependents (Vabret, 2016). In a competitive situation on the sports field, players are inundated with sensory information and experience fierce competition between cognitive tasks and postural control. However, it should be noted that attentional capacities, through competition between several tasks, deteriorate in terms of decreased mental performance.

Alcohol poisoning causes social problems with serious and significant behavioral consequences (Rhem, 2011). First of all, alcohol abuse can cause many cognitive disorders, thus paving the way for difficulty in emotional management that can distort communication between team members. Of which one of the determining elements of cohesion (Cox, 2013) should absolutely be preserved between athletes. Unfortunately, the ethyl toxicity triggers debilitating excitations which set up excessive crises in a team. One of the visible consequences remains the difficulty in coordinating efforts to the detriment of individualism on the sports field in groups as well as the decline in self-determined individual motivation (Reeve, 2017) among victims of the verbal crisis.

The other side of the consequence would be expressed in terms of the ineffectiveness of the group in the event of loss of trust between athletes. Indeed, if the players taken individually can have great self-confidence, the wrong answers or the hurtful remarks that one of the athletes would make should undoubtedly affect the positive of a teammate and ultimately cast doubt on the effectiveness, of the team. If the team as such does not share the sense of collective effectiveness, they will not evolve as a united block (Heuze \& Thomas, 2007). Thus, in the sporting experience, "being a confirmed player" or "being a beginner" should not be the only criteria to show cohesion. But the results of this research show that it is better to avoid cognitive alcohol intoxication as an active athlete because it is an essential clue to being able to preserve collective stability in the team.

Being neurotoxic, alcohol can be responsible for traumatic brain damage, the symptoms of which are cognitive deterioration such as intellectual capacities or memory functions, but also behavioral problems, belligerence, and aggressiveness. In addition, not only that alcohol consumed is directly linked to the rate of injuries sustained during sporting events, but also and above all its excessive consumption is one of the riskiest tasks that can worsen the health of athletes in the event of physical injuries. Since alcohol can prevent blood from clotting 
while blood clotting allows the individual to survive injury by preventing blood leakage. Otherwise, chronic alcohol consumption can predispose to bleeding in the event of injury (Salem \& Laposata, 2005; El-Sayed et al., 2005).

\section{Conclusion}

Our results have revealed that alcohol has almost degraded the attentional capacities of the central nervous system (Boisgontier, 2011) of athletes. Certainly, the ethyl toxicity damaged both the gray matter and the white matter of the players who abused it. However, gray matter damage causes obvious impacts on the frontal cortex, the cerebellum, the cingulate cortex, the thalamus, and the hippocampus. And that the attacks of the white matter denature the corpus callosum, the brainstem, and the bridge. This point of view corroborates with the study carried out by (Zachry et al., 2005) whose results confirmed that, from a neurological point of view the degradations on attention would be focused on movement than on postural control of the athlete himself. Likewise, our results show that alcohol impairs mental performance in general and attentional performance in particular, going so far as to prevent athletes from celebrating the experience of mindfulness which fundamentally depends on the efficiency of selective attention (Décamps, 2012). This hypothesis was validated by (Target \& Petitjean, 2016) when he showed in his study of elite athletes from different disciplines, including handball and sprinting, that selectivity and attentional power were predictive of mental performance, on the sports field.

\section{Conflicts of Interest}

The authors have no conflicts of interest.

\section{References}

Abernethy, B. (2001). Attention. In R. N. Singer, H. A. Hausenblas, \& C. M. Janelle (Eds.), Handbook of Sport Psychology (2nd ed., pp. 55-85). New York, NY: Wiley.

Astley, J., Magnuson, S. I., Omnelll, L. M., \& Clarren, S. K. (1999). Fetal Alcool Syndrome: Changes in Craniofacial Form with Age, Cognition, and Timing of Ethanol Exposure in the Macaque. Teratology, 59, 163-172. https://doi.org/10.1002/(SICI)1096-9926(199903)59:3\%3C163::AID-TERA8\%3E3.0.CO ;2-8

Barnes, M. J. (2014). Alcohol: Impact on Sports Performance and Recovery in Male Athletes. Sports Medicine, 44, 909-919. https://doi.org/10.1007/s40279-014-0192-8

Battaglia, N., \& Gierski, F. (2014). L'addiction chez les adolescents: Psychologie de la conduite addictive: Cannabis, alcool, alimentation, jeux vidéo, jeux d’argent (pp. 256). Bruxelles: De Boeck Supérieur.

Ben Amar, M. (2007). Les psychotropes criminogènes. Criminologie, 40, 11-30. https://doi.org/10.7202/016013ar

Berthoz, A. (2009). La Simplexité (pp. 256). Paris: Éditions Odile Jacob.

Boisgontier, M., Mignardot, J.-B., Nougier, V., Olivier, I., \& Palluel, E. (2011). Le coût attentionnel associé aux fonctions exécutives impliquées dans le contrôle postural. Science \& Motricité, 74, 53-64. https://doi.org/10.1051/sm/2011106 
Briefer, J.-F. (2012). Intégration sociale et psychopathologique chez les usagers de drogues. Une approche psychosociologique des facteurs de désinsertion sociale chez les héroinomanes en cure de methadone (pp. 465). Saarbrücken: Editions Universitaires Européennes.

Broadbent, D. E. (1958). Perception and Communication. New York, NY: Oxford University Press. https://content.apa.org/doi/10.1037/10037-000

Brust, J. C. M. (2010). Ethanol and Cognition: Indirect Effects, Neurotoxicity and Neuroprotection: A Review. International Journal of Environmental Research and Public Health, 7, 1540-1557. https://doi.org/10.3390/ijerph7041540

Cabé, N., Lanièpce, A., Boudehent, C., Pistel, A.-L., \& Vabret, F. (2018). Atteintes cognitives liées au trouble de l'usage d'acool: Rétablir l'équilibre? La Presse Médicale, 47, 565-574. https://doi.org/10.1016/j.lpm.2018.01.017

Cabé, N., Lanièpce, A., Boudehent, Vabret, C. F., \& Pistel, A.-L. (2019). Reperage des troubles cognitifs liés à l'alcool. Larevue du praticien, 69, 904-908. https://www.larevuedupraticien.fr/article/reperage-des-troubles-cognitifs-lies-lalcool

Carey, K. B. (2002). Clinically Useful Assessments: Substance Use and Comorbid Psychiatric Disorders. Behavior Research and Therapy, 40, 1345-1361. https://doi.org/10.1016/S0005-7967(02)00039-6

Cox, R. H. (2013). Psychologie du sport (2 ed., pp. 527). Bruxelles: De boeck.

Dany, L., Gaussot, L., \& Lo Monaco, G. (2015). L'alcool: Un objet au cœur du social. Les Cahiers Internationaux de Psychologie Sociale, 3, 299-302.

Décamps, G. (2012). Psychologie du sport et de la performance ( $1^{\text {re }}$ édition, pp. 431). Louvain-la-Neuve: De Boeck supérieur.

El-Sayed, M. S., Ali, N., \& Ali, Z. E. (2005). Interaction between Alcohol and Exercise. Physiological and Haematological Implications. Sports Medicine, 35, 257-269. https://doi.org/10.2165/00007256-200535030-00005

Ewart, F. G., \& Cutler, M. G. (1979). Effects of Ethyl Alcohol on Development and Social Behavior in the Offspring of Laboratory Mice. Psychopharmacology, 62, 247-251. https://doi.org/10.1007/BF00431955

Gorwood, Ph. (2019). Approche psychiatrique: Prévenir et soigner les 18-30 ans. In M. Choquet, \& C. Moreau (Eds.), Dans Les jeunes face à l'alcool (pp. 233-263). Toulouse: Érès. https://doi.org/10.3917/eres.choqu.2019.01.0233

Grossbard, J., Hummer, J., LaBrie, J., Pederson, E., \& Neighbors, C. (2009). Is Substance Abuse a Team Sport? Attention to Team, Perceived Norms, and Alcohol and Marijuana Use among Male and Female Intercolleigiate Athletes. Journal of Applied Sport Psychology, 21, 247-261. https://doi.org/10.1080/10413200903019145

Heuze, J. P., \& Thomas, J. (2007). Should the Coaches of Elite Female Handball Teams Focus on Collective Efficacy or Group Cohesion? The Sport Psychologist, 21, 375-382. https://doi.org/10.1123/tsp.21.4.383

Ismail, Z., Rajji, T. K., \& Shulman, K. I. (2010). Brief Cognitive Screening Instruments: An Update. International Journal of Geriatric Psychiatry, 25, 111-120. https://doi.org/10.1002/gps.2306

Kalivas, P. W., \& Volkow, N. D. (2005). The Neural Basic of Addiction: A Pathology of Motivation and Choice. American Journal of Psychiatry, 162, 1403. https://doi.org/10.1176/appi.ajp.162.8.1403

LaBrie, J. W., Grossbard, J. R., \& Hummer, J. F. (2009). Normative Misperceptions and Marijuana Use among Male Female College Athletes. Journal of Applied Sport Psychology, 21, S77-S85. https://doi.org/10.1080/10413200802582839 
Lemaire, P. (2006). Psychologie Cognitive (pp. 576). Bruxelles: De Boeck.

Martens, M. P., Dams-O'connork, K., \& Duffy-Paiement, C. (2006). Comparing Off-Season with In-Season Alcohol Consumption among Intercollegial Athletes. Journal of Sport \& Exercice Psychology, 28, 502-510. https://doi.org/10.1123/jsep.28.4.502

Mellers, B. A., Schwartz, A., \& Cooke, A. D. J. (1998). Judgment and Decision Making. Annual Review of Psychology, 49, 447-477. https://doi.org/10.1146/annurev.psych.49.1.447

Menecier, P. (2010). Ch.13-Recours à l'alcool et troubles cognitifs: Cause ou conséquence? In Dans Les Aînés et l’alcool (pp. 133-141). Toulouse: Érès.

Nasreddine, Z. S., Phillips, N. A., Bédirian, V., Charbonneau, S., Whitehead, V., Collin, I. et al. (2005). The Montreal Cognitive Assessment, MoCA: A Brief Screening Tool for Mild Cognitive Impairment. Journal of American Geriatrics Society, 53, 695-699. https://doi.org/10.1111/j.1532-5415.2005.53221.x

O’Brien, C. P. \& Lyons, F. (2000). Alcohol and the Athlete. Sports Medicine, 29, 295-300. https://doi.org/10.2165/00007256-200029050-00001

Oscar-Berman, M., \& Marinkovic, K. (2003). Alcoholim and the Brain: An Overview. AIcohol Research \& Health, 27, 125-133.

Pandza, F., Frisardi, V., Seripa, D., Logroscino, G., Santamato, A., Imbimbo, B. P., Scafato, E., Pilotto, A., \& Solfrizzi, V. (2012). Alcohol Consumption in Mild Cognitive Impairment and Dementia: Harmful or Neuroprotective? International Journal of Geriatric Psychiatry, 27, 1218-1238. https://doi.org/10.1002/gps.3772

Phélip, M. (2014). Le paradigme d'écoute dichotique: États des recherches et données développementales. Revue de neuropsychologie, 6, 59-68.

Pierucci-Lagha, A., \& Derousné, Ch. (2003). Alcool et vieillissement. Psychologie \& Neuro Psychiatrie du vieillissement, 1, 237-249.

Poucet, P. (2005). Vers une conception intégrative des processus de sélection pour la saccade et la perception. L'Année psychologique, 105, 697-739.

https://doi.org/10.3406/psy.2005.30500

Rault, A., \& Décamps, G. (2018). Le sport: Facteur de protection ou d'exposition au risque alcool ? Santé \& Société, larevuedupraticien, 68, 143-149.

Reeve, J. (2017). Psychologie de la motivation et des emotions (pp. 684). Bruxelles: De Boeck supérieur.

Rhem, J. (2011). The Risks Associated with Alcohol use and Alcoholism. Alcohol Research \& Health, 34, 135-143.

Ritz, L., Pitel, A. L., Vabret, F., Eustache, F., \& Beaunieux, H. (2012). Alcoolodépendance: Atteintes neuropsychologiques et diagnostics différentiels. Neuropsychology Review, 4, 196-205.

Salem, R. O., \& Laposata, M. (2005). Effects of Alcohol on Hemostasis. Pathology Patterns Reviews, 123, S96-S105. https://doi.org/10.1309/113N8EUFXYUECCNA

Sampson, P. D., Streissguth, A. P., Brookstein, F. L., \& Barr, H. M. (2000). On Categorization in Analyses in Analyses of Alcohol Teratogenesis. Environmental Health Perspectives, 108, 421-428. https://doi.org/10.1289/ehp.00108s3421

Scali, J., Loup, P., Siari, S. Gutierrez, Y., Grosclaude, P., Rotily, M., et al. (2002). La consommation d'alcool de jeunes adultes dans trois villes du sud de la France. Revue d'Epidémiologie et de santé publique, 50, 357-369.

Selzer, M. L. (1971). The Michigan Alcoholism Screening Test (MAST): The Quest for a New Diagnostic Instrument. American Journal of Psychiatry, 127, 1653-1658.

https://doi.org/10.1176/ajp.127.12.1653 
Selzer, M. L., Vinokur, A., \& VanRooijen, L. (1975). A Self Administered Short Version of the Michigan Alcoholism Screening Test (SMAST). Journal of Studies on Alcohol, 36, 117-126. https://doi.org/10.15288/jsa.1975.36.117

Seron, X., \& Van der Linden, M. (2014). Traité de neuropsychologie clinique de l'adulte: Tome 1-Evaluation (pp. 243). Louvain-la-Neuve: De Boeck Supérieur.

Serrao, H. F., Martens, M. P., Martin, J. L., \& Rocha, T. L. (2008). Competitiveness and Alcohol Use among Recreation and Elite Collegial Athletes. Journal of Clinical Sport Psychology, 2, 205-215. https://doi.org/10.1123/jcsp.2.3.205

Sesar, K., Barisic, M., Pandza, M., \& Dodaj, A. (2014). The Relationship between Difficulties in Psychological Adjustment in Young Adulthood and Exposure to Bullying Behavior in Childhood and Adolescence. Acta Medica Academica, 41, 131-144. https://doi.org/10.5644/ama2006-124.46

Singh, C. M., \& Heberlein, U. (2000). Genetic Control of Acute Ethanol-Induced Behaviors in Drosophila. Alcoholism: Clinical and Experimental Research, 24, 1127-1136. https://doi.org/10.1111/j.1530-0277.2000.tb02075.x

Smith, T., Gildeh, N., \& Holmes, C. (2007). The Montreal Cognitive Assessment: Validity and Utility in a Memory Clinic Setting. The Canadian Journal of Psychiatry, 52, 329-332. https://doi.org/10.1177\%2F070674370705200508

Target, C., \& Petitjean, I. (2016). La bible de la preparation mentale: La Méthode Target: de la théorie à la pratique (pp. 768). Paris: Amphora.

Tarroux, Ph., \& Auvray, M. (2012). Chapitre I: La perception visuelle. In M. Denis (Ed.), La Psychologie cognitive (pp. 36-39). Paris: Editions de la Maison des sciences de l'homme. https://doi.org/10.4000/books.editionsmsh.14769

Tsiama, P. J. A., Mabassa, D. S., Mabiala Nziedi, R. F., Koulombo, U. A., \& Mandoumou, P. (2019). Prédictions des Symptômes Dépressifs sur la Cognition des Entraîneurs Congolais. Journal of Sports and Physical Education (IOSR-JSPE), 6, 26-34.

Vabret, F., Lannuzel, C., Ritz, L., Boudehent, C., Eustache, F., Lise Pitel, A., \& Beaunieux, H. (2016). Troubles cognitifs liés à l'alcool: Nature, impact et dépistage. La Presse Médicale, 45, 1124-1132. https://doi.org/10.1016/j.lpm.2016.01.030

Varlinskaya, E. L., \& Spear, L. P. (2015). Social Conséquences of Ethanol: Impact of Age, Stress and Prior History of Ethanol Exposure. Physiology \& Behavior, 148, 145-150. https://doi.org/10.1016/j.physbeh.2014.11.062

Wilson, S. J., Sayette, M. A., \& Fiez, J. A. (2004). Prefrontal Responses to Drug Cues: A Neurocognitive Analysis. Nature Neuroscience, 7, 211-214. https://doi.org/10.1038/nn1200

Yanni, P. A., \& Lindsley, T. A. (2000). Ethanol Inhibits Development of Dendrites and Synapses in Rat Hippocampal Pyramidal Neuron Cultures. Developmental Brain Research, 120, 233-243. https://doi.org/10.1016/S0165-3806(00)00015-8

Zachry, T., Wulf, G., Mercer, J., \& Bezodis, N. (2005). Increased Movement Accuracy and Reduced EMG Activity as the Result of Adopting an External Focus of Attention. Brain Research Bulletin, 67, 304-309. https://doi.org/10.1016/j.brainresbull.2005.06.035

Zeisser, C., Stockwell, T. R., Chikritzhs, T., Cherpitel, C., Ye, Y., \& Gardner, C. (2013). A Systematic Review and Meta-Analysis of Alcohol Consumption and Injury Risk as a Function of Study Design and Recall Period. Alcoholism: Clinical and Experimental Research, 37, E1-E8. https://doi.org/10.1111/j.1530-0277.2012.01919.x 